\title{
O QUE É SER PROFESSORA DE FILOSOFIA NO ENSINO MÉDIO DA ESCOLA PÚBLICA BRASILEIRA?
}

\author{
WHAT IS BEING A PHILOSOPHER TEACHER OF BRAZILIAN PUBLIC HIGH SCHOOL?
}

\author{
Rafaela Antunes Nunes ${ }^{1}$
}

\section{RESUMO}

O objetivo deste trabalho é relatar a experiência vivida como estudante de licenciatura em Filosofia do Programa de Residência Pedagógica da UFRGS durante o ano de 2019 no Colégio Estadual Coronel Afonso Emílio Massot em Porto Alegre, RS. O relato em questão é voltado para principalmente uma pergunta que tem marcado profundamente minha experiência: o que é ser professora de filosofia no ensino médio da escola pública brasileira? Desde o início do ano letivo na turma 106 do Colégio Massot, houve forte predisposição dos alunos com a disciplina e com o modo como as aulas e discussões eram conduzidas, bem como a percepção de que muitas vezes o espaço da nossa aula era um espaço motivador, desafiador e até esperado. Porém, por diversas vezes, foi notado que essa predisposição não era suficiente para a obtenção de resultados mais objetivos e profundos em relação ao aprendizado. Esses resultados começaram a ser alcançados a partir do momento em que eu consegui aplicar em sala de aula a noção de diálogo, uma noção pouco tradicional, pois é vista como elemento fundamental para a possibilidade do aprendizado - uma vez que é apenas através dessa que se alcança o elemento mais importante do aprendizado, aquilo que chamo de resíduo. Entender como todos esses processos e práticas didáticas se deram, apontando seus resultados e podendo explicar de que maneira tal experiência caracteriza, ou pode caracterizar, a experiência de ser professora de filosofia de adolescentes no Brasil atual é o que pretendo contar.

Palavras-chave: Filosofia; Diálogo; Aprendizado; Programa de Residência Pedagógica.

\section{ABSTRACT}

The objective of this paper is to report the experience lived as a teaching graduate student in Philosophy of the Program of Pedagogical Residency, during 2019 at the Colégio Estadual Coronel Afonso Emílio Massot in Porto Alegre, RS. This report is mainly concerned with a question that has been marking profoundly my experience: what is being a philosopher teacher of Brazilian Public High School? Since the beginning of school year in class 106 from Massot School, there was a strong disposition of the students with the discipline and how classes and discussions were conducted, as well as a perception that the space of our class often was a motivating, challenging and even intended space. However, on several occasions, it was observed that this disposition was not enough to obtain more objective and profound results in relation to learning. These results started to be achieved from the moment in which I managed to apply in the classroom the notion of "dialogue", an unconventional notion, because it is seen as a fundamental element for the possibility of learning - since it is only through this that the most important element of learning is reached, what I call "residual". Understanding

1 Rafaela Antunes Nunes é Licenciada em Letras (UFRGS) e licencianda em Filosofia (UFRGS). E-mail: rafaelaantunesnunes@ gmail.com 
Thaumazein, Ano IX, v. 13, n. 25, Santa Maria, p. 97-109, 2020.

how all these didactic processes and practices occurred, pointing out their results and being able to explain how this experience characterizes, or can characterize, the experience of being a philosophy teacher for teenagers in Brazil today is what I intend to tell.

Keywords: Philosophy; Dialogue; Learning; Program of Pedagogical Residency.

\section{INTRODUÇÃO}

No decorrer de uma trajetória enquanto estudante da rede pública de ensino e da universidade federal, ocorreu o estágio da minha graduação de Licenciatura em Filosofia no Colégio Emílio Massot². Não foi a primeira experiência como professora - leciono há sete anos -, tampouco a primeira vez que encarava uma turma grande de adolescentes de uma escola pública e estadual, mas era a primeira vez que daria aulas regulares de Filosofia durante o período de quase um ano inteiro. Tal contexto me causava uma série de expectativas e medos, mas o principal deles era: ser professora dessa forma - de Filosofia no ensino médio da escola pública brasileira - daria certo?

Essa pergunta atravessou e continua atravessando grande parte da minha experiência lá no Massot e todos os desdobramentos que vêm acontecendo a partir disso. E aqui entram todas as contradições que a pergunta pode carregar: as representações políticas e sociais do que é ser professor hoje no Brasil e no estado do Rio Grande do Sul, as condições objetivas e práticas do que é dar aula no ensino público, as dificuldades passadas, presentes e futuras de ser estudante e professora de Filosofia e, não menos presentes, as contradições da minha trajetória pessoal ao apostar em lecionar.

O curso regular de Filosofia da Universidade Federal do Rio Grande do Sul (UFRGS) conta com três disciplinas de estágio nos três últimos semestres da graduação. Nessas disciplinas é esperado que o aluno ou aluna cumpra uma sequência de poucas aulas planejadas e ministradas no ensino médio - não mais que oito aulas por semestre. No ano de 2018, surge o Programa de Residência Pedagógica, um novo programa financiado pela Capes, e que faz parte de ações que integram a Política Nacional de Formação de Professores ${ }^{3}$. A Residência Pedagógica tem como objetivo principal a imersão maior na escola de educação básica e, por isso, a oportunidade de uma carga maior de horas aulas regidas. O que vi na oportunidade de ser residente foi a possibilidade de ser professora integralmente de uma turma, o que o estágio normal não me garantiria. E, à parte o segundo semestre de 2018 - que foi dedicado às orientações com os coordenadores, observações da escola e turmas, planejamento didático, reuniões e organizações gerais -, foi exatamente o que pude vivenciar no Colégio Emílio Massot. No ano de 2019, assumi então durante o ano inteiro uma turma de primeiro ano ${ }^{4}$ : a turma 106.

Minha turma tinha alguns diferenciais em relação às outras turmas da escola, no início do ano eles eram muito agitados, saíam e voltavam com frequência da sala de aula e não sabiam escutar o professor e/ou os colegas durante as aulas. No princípio, tentei me adequar mais aos métodos tradicionais de ensino:

2 Colégio Estadual Coronel Afonso Emílio Massot situado no bairro Cidade Baixa, na cidade de Porto Alegre/RS.

3 A Política Nacional de Formação de Professores é uma política pública implementada pelo Governo Federal no ano de 2017, que além de investimentos econômicos na área da educação, abrange também a criação de uma Base Nacional Docente até a ampliação da qualidade e do acesso à formação inicial e continuada de professores da educação básica.

4 As idades da turma variavam entre 15 e 18 anos. 
priorizar apenas as matérias que nos eram exigidas para passar em aula, dar mais exercícios e cobrar provas. Houve momentos que essas práticas funcionaram, outros em que eu ou eles poderíamos ter nos saído melhor. Porém, os problemas apresentados no início do ano continuavam. O que fazer para alterar aquilo?

Aqui é importante frisar, ainda que seja algo dito com bastante frequência acerca da adolescência, que existem diversos elementos sobre a mesma que passam despercebidos pelos regentes de classes. A adolescência, ainda, por diversas vezes, é impenetrável. Sem querer desvendar as inúmeras causas para tanto, acredito que aquilo que em muitas circunstâncias cobramos deles, nós não fazemos. Verbos básicos: prestar atenção, olhar, ver, tentar entender, parar, querer mudar. Tirando a romantização ou banalização que pode haver em torno de atitudes como essas, nós não as praticamos. São atitudes que dificilmente chegam à prática cotidiana. Eu, como que levada por esse estado de ânimo, também demorei a conseguir olhar para eles. E quando o fiz - mais uma vez tentando não cair em romantizações ou banalizações - o que encontrei não foi tão diferente da minha própria experiência escolar na educação básica, que pode ser colocada à luz da experiência dos meus alunos e vice-versa.

A verdade é que quando confrontada pelos problemas apresentados pela minha turma no Massot foi inevitável não perceber as inúmeras semelhanças entre a experiência deles e a minha, apesar dos 11 anos que, hoje, separam as duas. Assim, talvez tenha sido fácil admitir que a minha experiência enquanto professora, de modo autônomo pelos seis anos antes, e quem sabe, regular, a partir da turma 106, seja de bem antes de cumprir a função de professora e, sim, começou quando era aluna. Ser aluna do ensino médio da escola pública - ao contrário do que fui no ensino fundamental - foi algo desastroso e uma experiência de bastante opressão, uma experiência que quase denota um desejo pelo esquecimento. Sou e sempre fui filha e sobrinha de professora e a primeira escola da qual fui parte é a escola que elas construíram num bairro quase rural de Viamão, região metropolitana de Porto Alegre. Por muitas vezes me perguntei se a boa primeira experiência de escola teria se dado pelo fato de elas estarem ali, sempre presente. Demorei até tempo demais para concluir que não, elas existirem nesse espaço era só um detalhe dentre tantos outros bem-sucedidos daquele ambiente escolar.

A experiência que veio em seguida marcou tanto a minha maneira de enxergar a escola pública que me fez jamais cogitar ser professora. Eu queria de fato esquecer a escola. Se havia concluído esse ciclo, por que voltar a ele? Apesar de sempre ouvir de colegas na escola e de pessoas próximas de fora dela que eu tinha o dom de ensinar e de democratizar o conhecimento, não parecia haver qualquer motivo para repensar a experiência em si ou o possível retorno a ela, ainda que em uma posição diferente. Quando mais tarde prestei vestibular, decidi então que faria Letras Bacharelado, muito para fugir da licenciatura, o que fiz até quase concluir o curso de tradutora e revisora. Dois elementos me fizeram repensar a trajetória até ali, o fato de que a tradução não me trazia prazer algum, apesar também de ser uma atividade que aprendi a executar bem, e aquilo que identifiquei como meu desejo primeiro: o gosto por estudar. O que me dava prazer era estudar, a pesquisa, a leitura, o desenvolvimento e crescimento humano que acontecia a partir disso. Então, arrisquei, começando com aulas particulares de inglês e de reforço escolar. Sempre trabalhei desde os 16 anos de idade e pela primeira vez na vida ganhar dinheiro nunca pareceu tão simples, fácil e divertido.

O restante se deu de maneira fluída, decidi tentar mais e fazer licenciatura. Me graduei em Letras, e tentei ingresso diplomado. Naquele ano não havia vagas para Letras. Mas havia para Filosofia. 
Aquele curso estranho, pouco promissor levando em conta o pouco valor comercial e de reconhecimento que ele trazia, mas do qual eu tinha várias leituras na minha bagagem intelectual. Entrei para Filosofia em 2015. E cá estou: apaixonada por ela.

Minha primeira experiência com a licenciatura em Filosofia foi com uma atuação na escola Padre Reus, na Zona Sul de Porto Alegre, através do PIBID UFRGS (Programa Institucional de Bolsas de Iniciação à Docência). Quando entrei na escola, no primeiro dia, me senti extremamente desconfortável: o que eu fazia ali? Os questionamentos do final da adolescência voltaram: que grande professora eu seria uma vez que como aluna tinha tido péssimas experiências dentro da escola? Esse sentimento foi aos poucos se dissipando. A vivência do Padre Reus - e aquela de um grupo de estudos sobre feminismo que eu e outra colega criamos lá - me fez enxergar a escola de outra forma. A escola de ensino médio podia ser diferente diferente daquela que conheci quando era aluna - e a Filosofia parecia que podia ajudar muito nisso.

Em seguida, a Residência Pedagógica, ou o estágio no Massot, veio para me mostrar - e é com tristeza e com certo pudor que verbalizo - que em alguns aspectos a escola continua a mesma: ainda existem métodos ultrapassados de ensino, existem professores não dispostos a ouvir seus alunos, uma carência enorme dos alunos e ainda, na maior parte dos casos, falta o desejo de aprender. E sobre este último ponto, não falo só dos alunos, falo também de seus professores. E então uma questão a ser colocada - e, que talvez, infelizmente, não seja central aqui é: como você ensina sem ter prazer com o que ensina? É possível? E em segundo, duas questões que pretendo responder minimamente através do relato das minhas experiências enquanto professora da 106: se o espaço de aula deve ser desejado por aluno e professor para que haja aprendizado, como esse espaço deveria ser? E se se trata de desejo, como o despertamos nesse contexto?

\section{JUSTIFICATIVAS E METODOLOGIAS GERAIS}

As dificuldades relembradas e revividas da minha época escolar começaram aos poucos a se entrelaçar com as da sala de aula enquanto professora. Percebi que tudo o que eu ainda abominava sobre a escola era o que meus alunos também não suportavam sobre a mesma e percebi que aquilo que eu conseguia criar em pouquíssimos espaços da minha existência também faltava ali: o tempo e o diálogo. Parece uma forma simples e muitos dirão que a escola pública já criou o espaço do tempo e do diálogo. Minha tese baseada nessas experiências é de que não ou não na sua grande maioria. Nós abominamos não ter tempo, sermos adultos cheios de compromissos, sermos a "sociedade do cansaço e do desempenho" como Byung-Chul Han descreve no livro de sua autoria, Sociedade do Cansaço, e à medida que o tempo nos escapa, há pouco espaço para o livre pensar, para o se dar conta de que é preciso prestar atenção às coisas enquanto elas acontecem para buscar soluções.

O tempo é, sim, um privilégio, desde as sociedades mais primitivas, desde o surgimento da filosofia e da escola na Grécia Antiga. O termo escola, afinal, para quem ainda não sabe, vem do grego scholé significando "tempo livre" e como Jorge Larrosa descreve no livro Esperando não se sabe o quê - Sobre o ofício de professor, a função última da escola deveria ser criar esse tempo livre em que ela existiria única e exclusivamente para o aprendizado e o mestre nesse sentido teria a função de manejar o tempo: 
Thaumazein, Ano IX, v. 13, n. 25, Santa Maria, p. 97-109, 2020.

O que o mestre maneja (...) são as artes do tempo, as artes de fazer tempo, de dar tempo, de organizar e orientar o tempo. Não um tempo que já seja seu, mas um que nasce da própria aula (...). "Um tempo vibrante e calmo; um despertar sem sobressaltos. E é o mestre, sem dúvida, o que o permite surgir, fazendo com que o aluno sinta que tem todo o tempo para descobrir e para ir descobrindo a si mesmo". (LARROSA, p. 334, 2018)

O que almejei e fiz com meus alunos foi criar o tempo do diálogo. Aparentemente ali pouco se ouvia, independente da fala ser minha ou de algum outro aluno, isso somado às inúmeras interrupções que às vezes ocorrem na comunidade escolar - o tempo aparentemente escasso dos períodos de aulas e, mais escasso ainda aquele disponível para as aulas de Filosofia (uma média de um a dois períodos na grade escolar atual no Brasil), problemas de infraestrutura pública, problemas pontuais e gerais da convivência coletiva, entre outros - tornou a nossa aula e torna o ambiente da sala de aula de um modo geral uma luta para entender e driblar os constantes estímulos para o não-diálogo.

Eu poderia ser questionada: e o tempo do aprendizado, onde fica, onde encontramos, como o encontramos? O que concluí ao olhar e observar a cultura escolar do Emílio Massot é que havia um enorme potencial na escola e na equipe diretiva, e principalmente nos seus alunos. Os olhos deles ainda brilhavam de curiosidade sobre alguma nova informação nunca ouvida, se mantinham atentos acerca da nova professora de Filosofia que estava à frente deles, moviam-se rapidamente ao ouvirem uma pergunta filosófica bem feita e bem colocada. Mas, não era suficiente, não estava havendo, ainda, o aprendizado. Havia algo para além das condições racionais e reflexivas dos alunos que me impedia de dar uma boa aula. É claro que a conexão emocional com eles era importante, e já estava acontecendo, porém, também, se fazia necessário buscar algo que estimulasse o tal aprendizado com resultados objetivos. E, nesse sentido, a mim parecia que a condição básica para isso se formar seria apostar na ideia de diálogo, ou seja, uma conversa concreta em que houvesse interlocutores e locutores, o que não havia naquela sala. Os alunos reagiam com atenção e interesse ao que estava sendo dito, porém a relação que eles mantinham não era com um indivíduo falante, mas, sim, com uma figura que transmitia ideias excitantes e curiosas, e com as quais eles simplesmente mantinham uma relação ideal ou abstrata. Ao final desse jogo de informações (e não de mensagens), o resultado era de alunos entretidos com ideias que não eram exatamente associadas com eles próprios: faltava concretude, que se materializa apenas através da experiência de pessoas com essas ideias. Assim, como o fundamento do diálogo é a noção prática da pessoalidade, o aprendizado ainda precisava dessas categorias dirigindo e organizando a vivência escolar.

Em vista desse objetivo maior, estimular o diálogo, para posteriormente se obter aprendizado, busquei a revisão atenta de algumas leituras base do movimento feminista, assim como textos mais atuais que defendem uma visão específica do que podemos entender por diálogo. Foi revisitada a obra de Simone de Beauvoir, O Segundo Sexo, apenas como uma forma de mais uma vez reconstruir algumas correlações dessa obra com os argumentos presentes nas duas outras principais obras feministas utilizadas para embasar essa sequência de aulas: Feminismo em comum: Para todas, todes e todos, da Marcia Tiburi, e Lugar de Fala, da Djamila Ribeiro 5 .

5 O conteúdo dessas obras e os conceitos de Lugar de Fala e Lugar de Escuta presentes nas mesmas não foram utilizados através do viés antropológico e histórico, que é a marca mais distintiva nesses dois textos. O uso desses conceitos tinha como fim construir a capacidade e sensibilidade dos alunos de analisar a praticabilidade de suas vidas e dos conhecimentos 
Essas obras e esse objetivo principal, a aposta no diálogo, foram também pensados em vista de uma adequação às principais competências voltadas para o Ensino Médio presentes na Base Nacional Comum Curricular (BNCC). As competências filosóficas que se esperava que fossem desenvolvidas pelos alunos e alunas através das atividades presentes aqui são aquelas que encontramos mais precisamente na seção Área de Ciências Humanas Sociais Aplicadas, que defendem o diálogo e a argumentação efetiva como fontes necessárias para estabelecer as condições do conhecimento:

[...] Jovens constroem hipóteses e elaboram argumentos com base na seleção e na sistematização de dados, obtidos em fontes confiáveis e sólidas. A elaboração de uma hipótese é o primeiro passo para o diálogo, que pressupõe sempre o direito ao contraditório. É por meio do diálogo que os estudantes ampliam sua percepção crítica tanto em relação à produção científica quanto às informações que circulam nas mídias, colocando em prática a dúvida sistemática, elemento essencial para o aprimoramento da conduta humana. (...) Todavia, a identificação de uma questão, a realização de recortes e a interpretação de fenômenos demandam uma organização lógica, coerente e crítica para a elaboração das hipóteses e para a construção da argumentação em torno das categorias selecionadas. Nas Ciências Humanas e Sociais Aplicadas, analisar, relacionar, comparar e compreender contextos e identidades são condições para conhecer, problematizar, criticar e tomar posições. (BRASIL, p. 548 e 549, 2018)

Tais competências são essenciais ao ensino de Filosofia, mas também podem e devem ganhar o espaço das demais disciplinas escolares e, mesmo que não sejam tratadas diretamente por essas, as aulas de Filosofia podem ser úteis na medida em que conjuntamente com o diálogo e argumentação, exercem competências que também aparecem nas demais disciplinas, como: leitura, análise, interpretação, escrita, correlações de informações ou premissas, etc. Além disso, é crucial salientar que ainda que esta sequência tenha mobilizado conceitos elaborados e tratados por textos filosóficos, o que estava em jogo não era apenas a apreensão de conceitos filosóficos, mas, sim, principalmente, a competência base para adquirir qualquer tipo de conhecimento, quer dizer, o diálogo. Aspecto esse que as feministas contemporâneas, tendo em vista uma preocupação prática, frequentemente reivindicam como importante.

\section{SEQUÊNCIA DE DUAS AULAS E RESULTADOS PARCIAIS}

A prática didática que carregou todos esses pressupostos foi uma sequência de duas aulas de dois períodos cada (50 minutos por período) para tematizar Lugar de Fala e Lugar de Escuta - para posteriormente também correlacionar com os conceitos de diálogo, argumentação e princípio de caridade. Na primeira aula foi pedido que os alunos circulassem em uma lista de nomes de sentimentos positivos aquele ou aqueles que sentiram mais recentemente e com maior intensidade e depois justificassem a escolha. O mesmo foi pedido num segundo exercício, mas desta vez com sentimentos negativos. A última pergunta consistia em responder "Você acha que o que você acabou de escrever na pergunta 1 e 2 pode ser considerado um tipo de conhecimento? Se sim, para que ele serviria?". Depois, fomos até o pátio da

com que entravam em contato. Ou seja, o foco foi oferecer conceitos mais voltados à análise cotidiana que apenas aqueles voltados à análise histórica e política das sociedades. 
escola, e pedi a alguns deles que contassem para o grupo suas respostas. Vários deles quiseram falar e foram realmente sinceros na sua fala e/ou escrita, inclusive contando sentimentos que talvez não fossem tão bem-recebidos ou bem-vistos por algum outro colega ou pelas figuras de autoridade que estavam ali - eu, a colega do estágio, Márcia Laux, e o professor da disciplina, João Paulo Silveira. Como forma de retribuir a coragem deles e mostrar que também podíamos ter sentimentos semelhantes, li a minha resposta e pedi que Márcia e João fizessem o mesmo.

A finalização desta aula consistiu em defender aquilo que fizemos ali como uma espécie de diálogo que promovia um espaço para o autoconhecimento, ou seja, a questão de número 3 poderia ser respondida de forma positiva. Perguntei a eles quantas vezes ou com qual frequência eles tinham um espaço semelhante na vida, o que na grande maioria foi respondido de forma negativa. Foi então que concluí dizendo que o terceiro trimestre seria uma forma de estudarmos e desenvolvermos aquelas habilidades por vezes esquecidas na nossa sociedade: lugar de fala, lugar de escuta e também para aprofundarmos as habilidades da argumentação - algo que já vínhamos fazendo desde o início do ano. Na sequência dessa aula, eu e o colega de estágio, Matheus Cenachi, fizemos uma prática do Teatro Fórum com os alunos - teatro criado pelo brasileiro Augusto Boal ${ }^{6}$, um método que reúne exercícios, jogos e técnicas teatrais elaboradas em conjunto por atores, diretor e público.

Foi encenada uma situação em que lugar de fala e lugar de escuta não eram em medida alguma respeitados, depois perguntamos se havia algo de errado com a cena e, se sim, o quê. Eles imediatamente conseguiram identificar elementos que prejudicavam o diálogo e, a partir disso, perguntamos o que poderia ser mudado. Uma das alunas que mencionou mudanças significativas foi convidada a atuar de modo a colocar aqueles novos elementos na cena. Esse exercício foi feito algumas vezes até que eu e Matheus não estivéssemos mais atuando e os alunos pudessem eles mesmos aplicar o conhecimento exposto em aula, o conhecimento prévio de vida de cada um e também o conhecimento emocional7, que era o pretendido ser despertado com a encenação. No final, foi então de fato conceituado Lugar de Fala e Lugar de Escuta.

Os conceitos de lugar de fala e lugar de escuta que foram utilizados e discutidos com os alunos não foram retirados diretamente de uma passagem específica dos livros das filósofas estudadas, mas foram adaptações de ideias defendidas nesses textos. Assim, lugar de fala foi conceituado como "é um espaço político e social que construímos no qual um indivíduo se utiliza da escuta e compreensão dos outros para expressar suas ideias, sentimentos e experiências" e lugar de escuta como "é um espaço político e social que construímos no qual um indivíduo se coloca à disposição para ouvir e compreender as ideias, sentimentos e experiências de outras pessoas" ${ }^{8}$. A partir disso, foi defendido para alunos a ideia de que somente quando tais espaços se cumpriam conjuntamente e fossem respeitados haveria um

6 Sobre Augusto Boal e sua obra: http://augustoboal.com.br/vida-e-obra/

70 conhecimento emocional que foi pretendido ser despertado pela prática do teatro nessas aulas pode ser compreendido de duas formas: aquilo que a encenação do dado momento causaria nos alunos a partir dos problemas representados e também como os mesmos poderiam, via associações internas, reviver emoções oriundas de situações particulares. Portanto, o objetivo dessa experiência era o de consolidar uma crença ou conceito anteriormente trabalhado, sua justificação, sua praticalidade e o seu estado conativo (motivacional) correspondente.

8 A simplicidade das formulações dos conceitos apresentados se deve principalmente como uma forma de atender ao público em questão. Se fazia necessário através das diferentes idades e níveis de maturidade presentes na turma 106 formulações mais objetivas que fossem não só de fácil acesso e compreensão, mas de fácil transposição prática-filosófica. 
diálogo, bem como, a partir dele, se poderia alcançar posteriormente o conhecimento (seja ele o prático, o psicológico ou propriamente filosófico).

A sequência posterior a esta apresentada foi a introdução à lógica. Foram apresentados e discutidos conceitos, definições e exemplos da lógica informal, como proposição, premissa, conclusão, argumento, tese, inferência, valor de verdade, argumento válido, argumento inválido e argumento sólido. Também foram explicadas e discutidas as relações da lógica e da argumentação com as noções apresentadas anteriormente de lugar de fala, lugar de escuta e diálogo. Nesse caso, o que foi ressaltado é a ideia de que se não nos dispormos verdadeiramente a escutar o que outra pessoa afirma ou defende, não somos capazes de compreender o argumento dessa pessoa, muito menos poder concordar ou discordar dela, uma vez que desconhecemos o conteúdo dessas afirmações ou teses. Além do cumprimento dos objetivos principais dessa segunda sequência - ensinar lógica, estimular a argumentação -, há nesse caso também uma série de elementos que contribuem para as relações de afeto e respeito ao que outra pessoa vive ou fala, elementos esses que mantêm uma íntima e implícita relação com as teses e crenças dos indivíduos, sendo, portanto, epistemicamente relevantes. Ainda que essas descrições de aulas executadas mostrem um cenário educacional muito rico, falta aqui ainda a exposição detalhada e completa daquilo que eu considero o elemento ou a fase mais importante da aprendizagem.

Uma vez que essa forma de diálogo defendida por mim se instaurou na nossa prática contínua de sala de aula, pôde-se observar interessantes resultados tanto a nível individual quanto a nível coletivo das alunas e dos alunos. A minha relação com aqueles indivíduos que foi sendo construída progressivamente desde o início do ano escolar de 2019 a partir dessa forma de diálogo e que teve seu fecho instrumental dado no contexto dessas duas sequências de aulas modificou significativamente o modo de operação da convivência (entre eles mesmos e entre eu e eles) e também da vontade de participar de processos de aprendizagem, bem como foi possível notar a presença mais significativa de resultados objetivos e profundos, uma vez que também houve mais envolvimento coletivo na busca por esses resultados.

Joaquim $^{9}$ era meu aluno mais difícil. Talvez o que tinha a vida mais humilde, bastante disperso, procurando se encontrar em uma turma majoritariamente mais avançada que ele e majoritariamente de pessoas brancas - na turma no início do ano havia contando com ele apenas dois ou três alunos negros, faltava ali um pouco de representatividade ${ }^{10}$ para ele. Às vezes se calava em meio a tantas vozes mais potentes ou raciocínios mais rápidos que o dele. Joaquim no seu primeiro trabalho escreveu duas linhas de resposta a uma pergunta relativamente simples e seguiu-se assim por um bom tempo. Demorei a perceber que não era falta de interesse, havia ali dificuldades reais, como: um raciocínio pouco estimulado e compreendido, que se mostrava através de dificuldades de interpretação e escrita, ausência completa

9 Os nomes utilizados para referenciar alunos da turma 106 são fictícios, um modo de preservar as identidades e histórias individuais.

10 Dentro de alguns estudos contemporâneos, principalmente relacionados à Ética e à Política, tem se estudado a representatividade, que de acordo com a grande maioria dessas teorias, é considerado o elemento crucial para que um indivíduo se sinta parte de uma sociedade enquanto um agente político e social. Ou seja, que ele tenha espaço político e social para utilizar a própria voz e corpo, bem como servir de modelo a ser seguido para outros indivíduos que partilham das mesmas características que ele. 
de encadeamento de ideias, orações extremamente simples que não davam conta da descrição mínima de um problema ou ideia. Joaquim era meu aluno analfabeto funcional.

Paulo era um aluno "do fundão". Era aquela pessoa que facilmente irritava os alunos que sentavam à frente da classe, causando perturbação às aulas, por meio de piadas grosseiras. Tinha uma frequência mediana e, quando presente, se recusava a fazer qualquer tipo de tarefa; quando fazia, eram cópias integrais de textos de outros colegas. A sua voz, como a de Joaquim, de certa forma, não aparecia, mas de um jeito diferente. Joaquim ainda era bastante interessado no espaço da sala de aula e tinha o que talvez possa se chamar de curiosidade filosófica. O que faltava para ele era, claro, sair dessa condição de analfabetismo funcional, ser ouvido pela professora num movimento de entendimento de suas dificuldades e pensamentos, mas também pela turma. Ele precisava existir para a sua turma.

Esse não era o caso de Paulo. Paulo estava desacreditado completamente pelos seus colegas e talvez pela maioria dos professores da escola. O que faltava era uma mudança de atitude dele em relação a si próprio e a turma precisava o ver também de outra forma. Os demais precisavam saber que Paulo poderia voltar a ser membro do grupo, que ele sabia arquitetar mais do que piadas grosseiras e bem formuladas.

Martha e Luís eram alunos medianos. Martha tinha pouca organização argumentativa, confusão na hora de falar e escrever e um grau de dispersão muito alto. Também pouca autoestima no início do ano: quando pedido que explicasse um conhecimento que tinha - prático, filosófico, científico, qualquer um - ela dizia que não sabia ou conhecia qualquer coisa que fosse e, mais, que eu estava ali para fazê-la conhecer. Luís prestava bastante atenção às aulas, se envolvia facilmente com as discussões filosóficas apresentadas, fornecia oralmente respostas perspicazes aos problemas, era bastante presente. Isso quando se encontrava realmente presente: tinha bem mais de $25 \%$ de falta no primeiro trimestre e eu não tinha absolutamente nenhum trabalho ou prova dele feito para poder avaliar ou conceder qualquer nota que fosse. Luís foi uma incógnita por alguns meses: estava com problemas em casa? Fugia das avaliações? Sabia ele que tinha um dom para a filosofia?

Marcelo e Emma eram casos meio complicados. Eram namorados - ainda o são - sentavam um ao lado do outro e no primeiro mês a vi continuamente dormir no colo dele em aula. No início, ela parecia apenas uma menina com muito sono que precisava estar na escola desde às 7h40min; ele, o namorado carinhoso que cumpria o protocolo de ser o estudante do ensino médio que precisava se formar. A princípio a estratégia foi começar por ela, pedindo apenas que tentasse não dormir, participar mais, fazer o mínimo. Se houvesse resultado, assim, quem sabe, se observaria se o namorado mudaria também um pouco de atitude ou permaneceria impassível. Emma, aos poucos, bem lentamente, começou a tentar mudar de atitude. Mas... Não era suficiente. Um dia, perguntei: por que tanto sono? A resposta veio direta e simples, com aquela lucidez que às vezes se tem nessa idade: "sora, eu trabalho das $14 \mathrm{~h}$ às $23 \mathrm{~h}$ ". Emma, acho que jamais vai saber ou entender verdadeiramente, mas ela talvez tenha completado o meu processo de ser professora. Ali eu percebi que quase nada do que eu faria em termos de pesquisa ou didática que já dominava os ajudaria a aprender qualquer uma dessas tantas manobras e questões filosóficas. Eu não poderia fazer com que Emma parasse de trabalhar, mas eu poderia estender ao máximo o tempo em que estivesse com ela e com todos os outros. 
É com certa tristeza que precisei selecionar alguns poucos exemplos, uma vez que o espaço da escrita não comporta o relato de uma turma de mais de 30 pessoas. O critério utilizado para essa seleção foi a simples progressão maior dos alunos mencionados e, por isso, uma clareza maior dos resultados que foram se apresentando. Porém, antes de expor os mesmos, é preciso finalmente discorrer sobre o que considero o elemento ou a fase mais importante da aprendizagem.

Antes de existir concretamente a real noção do diálogo nas aulas, faltava o que eu pretendo chamar de resíduo. Denomino resíduo o término de um complexo processo associativo do aluno, no qual diversas relações conceituais e semânticas são estabelecidas; relações estritamente linguísticas, relações emocionais, imagéticas, pessoais e interpessoais, etc. Utilizando termos mais tradicionais, a mim o aprendizado é composto por dois elementos fundamentais: a ostensividade ${ }^{11}$ e o resíduo. De modo mais simplificado possível, a fase ostensiva do aprendizado é aquela onde é estabelecida uma primeira, básica e superficial associação entre signo ou conjunto de signos e seus significados. Um exemplo disso, que acontecia no início do ano, era quando um aluno compreendia um conceito geral e sua definição, como o de ideologia. Se esse aluno compreendesse a definição apresentada, conseguindo também formular um exemplo da mesma, isso não era suficiente para que houvesse aprendizado, porque o ramo de aplicação conceitual dessas noções apresentadas era absolutamente ou radicalmente restrito, restrito a tal ponto que as justificativas para a sustentação dessas noções eram inexistentes ou extremamente vagas e incompletas. Agora, uma vez que esse mesmo aluno formasse uma complexa rede de associações com a definição de ideologia, ele conseguiria compreender também as diversas conexões que esse conceito cumpre na nossa vivência filosófica e prática, bem como seu papel na nossa vivência em sociedade. Então, dado que o ramo conceitual nesse caso é bem mais amplo, normalmente o entendimento desse conceito implica em sua justificação completa ou melhor estruturada. Assim, poderia ser dito que houve resíduo e, portanto, aprendizado.

A concepção conservadora de ensino, por exemplo, toma a fase da ostensividade como fim, isto é, como aprendizado; trata-se de uma perspectiva meramente conteudista, segundo a qual uma série pronta de "conhecimentos" é apenas entregue a um aluno. Embora esse sistema seja um tanto obsoleto, não é essa fase da aprendizagem dispensável: pois é ela base necessária para o passo posterior, o passo onde ocorre o resíduo. Em termos analíticos, o segundo passo é a continuação dessa primeira associação: trata-se de ampliar o campo relacional do conceito em questão, fazendo a compreensão dele, do sentido dele, ser, em verdade, determinado pela compreensão das muitas relações que esse conceito sustenta com as mais variadas coisas. Recorrendo a um jargão definitivamente filosófico, o aprendizado, aqui, está sendo compreendido e definido enquanto um holismo semântico-emocional'2.

11 Existe como fundo de inspiração para esta nomeação a ideia de "ensino ostensivo" de Wittgenstein, vide as Investigações Filosóficas.

12 A expressão acima utilizada não tem a pretensão de sustentar tal posição filosófica da maneira mais robusta possível, pois essa concepção não está sendo verdadeira e profundamente endossada aqui. O uso do conceito holismo semântico possui função figurativa na medida em que meu fim é apenas ilustrar as intensas semelhanças entre o que compreendo sobre as fases da aprendizagem e essa postura filosófica como um todo. Além disso, o que estou realmente ressaltando aqui é que as relações estabelecidas pelo aluno não são meramente ou se reduzem a conexões racionais, uma vez que a rede associativa depende e é constituída por associações ora inteiramente emocionais e pessoais ora por quaisquer outros elementos subjetivos. 
Assim, considero o resíduo o final desse processo associativo, que só é possível através da ideia aqui defendida de diálogo. A razão para isso é que: as primeiras complexas redes associativas de ideias são estabelecidas através de exemplos ou aplicações conceituais que partem e são direcionadas a pessoas (e a noção de pessoa só é vivida no e a partir do diálogo). Trata-se do simples movimento de associar um conhecimento ou tema abordado às vidas particulares de cada um, às vivências, memórias e aparto psicológico de cada indivíduo, processo esse que se dá apenas quando há diálogo ${ }^{13}$.

\section{CONCLUSÃO E RESULTADOS FINAIS}

A turma 106 ao final do ano letivo de 2019 passou a saber dialogar, bem como argumentar oralmente de forma organizada, ler e interpretar de forma razoável e passaram a escrever significativamente melhor. O diálogo interpessoal não se deu apenas de forma oral, mas também a partir de comentários em cada um dos textos ou provas que produziram. Eles escreviam e eu respondia a eles, alargando as possibilidades de interação conceitual, filosófica e pessoal. Todos obtiveram esse tipo de atenção em alguma medida e no nível individual foram pensadas e executadas estratégias que visavam a atender as dificuldades específicas de cada caso.

Joaquim começou a falar em aula, passou a conseguir levantar questões relevantes nos momentos argumentativos mais fundamentais e também a demonstrar o mínimo de esforço ao tentar responder a perguntas estritamente filosóficas. Joaquim, que escrevia duas linhas como resposta a qualquer pergunta em provas e trabalhos, ao final do ano, conseguia escrever um parágrafo bem concatenado, contendo as ideias principais de um problema, ainda que nem sempre argumentando perfeitamente. Ele passou a ter gosto por ouvir e ler a própria voz.

Paulo, que precisava ser visto de outra maneira pela turma, passou lentamente a demonstrar um novo comportamento, quando eu comecei a pedir a ele que contasse ou explicasse a turma um conhecimento que ele tinha - muitas dessas informações obtive por meio da simples observação do aluno ou em conversas com ele nos intervalos ou início das aulas. Paulo ainda continuava a fazer piadas, mas já não eram tão recorrentes, nem tinham o mesmo papel que outrora. Sobre as ideias que reproduzia e que não eram suas: durante todo o ano, incessantemente, foi só o que obtive dele. Nos últimos dois meses de aula, a surpresa: cinco linhas meio atrapalhadas e tímidas, mas suas.

Martha, com sua baixa autoestima, recebeu uma tarefa especial no primeiro mês de aula: escrever uma lista dos conhecimentos que possuía. Não aqueles que eu estava ensinando a ela, não os que as amigas possuíam. Ela, para a minha surpresa, fez a lista, me apresentou e durante um bom tempo, viu a filosofia como uma forma de investigação sobre o conhecimento ele mesmo e que fornecia instrumentos para a compreensão da sua vida ou da vida como um todo - o que, sabemos, não é tão distante do que ela é. Martha também foi a aluna, de certa forma corajosa, que contra-argumentou de forma bastante satisfatória uma tese sobre ideologia em uma das nossas provas, enquanto a maioria da turma, ainda que se saindo muito bem, não arriscou discordar do argumento contido no exercício.

13 As teses defendidas nessa seção acerca dos processos de aprendizagem foram construídas ao longo de bastante tempo conjuntamente com Matheus Cenachi. 
Com Luís, o jogo foi diferente. Muita conversa e incentivo para que estivesse mais presente e não largasse a escola, tentando mostrar que era um dos alunos mais ativos filosoficamente em aula. Levou meses para que escrevesse algo para mim, quando o fez, me deparei com uma interpretação argumentativa do movimento feminista tão lúcida, que me fez questionar como ainda era possível que mulheres depois de séculos lutassem para serem ouvidas. Luís certamente entendia o que homens muito mais cultos jamais irão entender.

Emma e Marcelo mudarão tanto. Ele passou, como que maravilhado e incentivado pela relação de Emma comigo, a prestar atenção em tudo a sua volta. Houve muito mais comprometimento, tentativas mais legítimas de compreensão dos problemas e produções escritas mais organizadas. Um dia, veio até mim tentando explicar uma ideia que teve sobre as teses de Platão e queria saber se fazia algum sentido, o que me disse tinha correlação direta com a Teoria da Reminiscência. Expliquei a ele um pouco da teoria e disse que se tivesse oportunidade tinha que dar continuidade a alguma leitura sobre o tema no futuro. Emma, não deixou de trabalhar, nem de na maior parte do tempo sentir-se cansada, mas os problemas interpretativos e a visão parcial e limitada que tinha acerca das verdadeiras questões filosóficas deram lugar a uma visão muito mais ampla e uma evolução na organização mental pouco comum para o tempo que tivemos de aula. Ela terminou o ano letivo tendo a melhor escrita filosófica da turma - sendo o seu ápice uma redação extremamente detalhada e com uma visão imparcial sobre a banalidade do mal de Hanna Arendt ao analisar o caso de Eichmann.

O que fiz com meus alunos foi criar o tempo do diálogo. Trazer as experiências deles para a sala de aula e dividir as minhas também. Foi tematizado e ensinado vários conteúdos filosóficos (conhecimento, crença justificada, ideologia, lógica, argumentação, realidade e aparência, etc), porém sempre despertando a discussão e o desejo antes do conteúdo em si e respeitando o tempo. Tudo o que fiz foi exigir deles, ou, melhor, dar a eles, o que eu esperava que tivessem dado a mim quando estava na escola de ensino médio e que tive parcialmente na escola de ensino fundamental: o respeito à minha fala e ao meu tempo. Houve espaços de autoconhecimento, diálogo sobre as experiências pessoais e durante a aula tentativas de entender as dificuldades, eu dei a eles, o que talvez alguns ali nunca tiveram em lugar algum: a escuta. E assim foi o suficiente para despertar o desejo de atenção em mim e no espaço da nossa sala de aula, todos evoluíram, todos cresceram, ainda que respeitando as particularidades de cada indivíduo da turma 106. Por fim, eu talvez tenha criado o que Julio Groppa Aquino chama de amizade intelectual ${ }^{1 / 4}$, quando mestre e aluno se permitem aprender juntos e quando a intensidade do diálogo ultrapassa os limites da sala de aula.

É importante ressaltar que tais habilidades e esse lugar conquistado com os alunos não é um processo que uma vez feito esteja garantido. Não estamos falando de um lugar seguro, o que fica de aprendizado para mim é que a sala de aula e as relações estabelecidas ali devem estar em constante manutenção, como qualquer outra relação que estabelecemos fora dela, para que haja crescimento ou o resíduo do aprendizado. Também, não menos importante, é necessário verbalizar que nem sempre a escola pública tem dado espaço e condições para que seus professores e professoras consigam estabelecer métodos mais avançados de ensino, uma vez que as condições de trabalho, sejam elas quais forem, ainda permanecem profundamente precárias.

14 Conceito presente no livro do autor Da autoridade pedagógica à amizade intelectual: uma plataforma para o éthos docente. 
Acredito que tenha ousado aprender verdadeiramente com meus alunos e não ensinei de modo a transmitir o conhecimento de forma tradicional. Foi um longo caminho até aqui, desde os meus primeiros anos escolares e desde as reflexões que pude também fazer a partir daquelas experiências. E enfim, nós, eu e a turma 106, escrevemos, dialogamos, construímos o nosso conhecimento juntos. Há quem diga que esse talvez seja o espaço privilegiado da Filosofia - e talvez de ser professor de filosofia - criar os espaços de diálogo, escuta, fala e argumentação. Mas se estamos de acordo que o desejo e o tempo são processos que atravessam todo aprendizado, arrisco dizer que o movimento pedagógico executado por mim nessa experiência poderia em algum grau ser executado por todas as demais disciplinas do currículo escolar.

\section{REFERÊNCIAS}

ARENDT, H. Eichmann em Jerusalém. São Paulo: Companhia das Letras, 1999.

AQUINO, J. G. Da autoridade pedagógica à amizade intelectual: uma plataforma para o éthos docente. São Paulo, SP: Cortez Editora, 2014.

BEAUVOIR, S. O Segundo Sexo, tradução Sérgio Milliet. Rio de Janeiro, RJ: Nova Fronteira, 2016.

BRASIL. Base Nacional Comum Curricular. Brasília: MEC/SEB, 2018. (3a versão)

HAN, B-C. Sociedade do cansaço, tradução Enio Paulo Giachini. Petrópolis, RJ: Nova Fronteira Editora, 2015.

LARROSA, J. "O Drama da Mediação". In: Esperando não se sabe o quê - Sobre o ofício de ser professor. Belo Horizonte, MG: Autêntica Editora, 2018, p. 332 - 339.

RIBEIRO, D. Lugar de Fala, Belo Horizonte: Letramento, 2017. (Feminismos Plurais)

TIBURI, M. Feminismo em comum: Para todas, todes e todos. $6^{\text {a }}$ ed. Rio de Janeiro, RJ: Rosa dos Tempos, 2018.

WITTGENSTEIN, L. Investigações Filosóficas. São Paulo: Edições Loyola, 2005. 
